\title{
Realizm ve Liberalizm Perspektifinde Arktik Bölge Güvenliği ve Süregelen Güvenlik İkilemi
}

\author{
DOI: 10.26466/opus.773799
}

$*$

\author{
Murat Yorulmaz * \\ * Dr. Öğr. Üyesi, Trakya Üniversitesi, Havsa Meslek Yüksekokulu, Edirne/Türkiye \\ E-Posta: muratyorulmaz2288@hotmail.com ORCID: 0000-0002-3664-0451
}

\section{Öz}

Küresel iklim değişikliğinin yol açtığı küresel ısınmanın artması ile birlikte Kutup bölgelerindeki buzulların erimesi neticesinde deniz ve deniz tabanının kullanilır hale gelmesi, zengin doğal kaynaklara sahip olması ve yeni deniz ticaret yollarına erişim kolaylı̆̆ı să̆layacă̆ı düşüncesi, Arktik bölgeyi küresel ölçekte siyasi ve ekonomik açıdan önemli kılmakta ve jeopolitik bir mücadele alanına dönüştürmektedir. Arktik bölge, günümüzde özellikle kendisine kıyıdaş olan ve 'Arktik Beşlisi' olarak adlandırılan $A B D$, Rusya Federasyonu, Kanada, Norveç ve Danimarka açısından siyasi ve ekonomik kazanımlar bağlamında rekabet alanı oluşturmakta ve bu devletler siyasi, ekonomik ve hatta bölgedeki ulusal güvenlik çıkarlarını korumak adına kara, hava ve deniz sahalarında askeri önlemleri ve yatırımları giderek arttırmaktadır. Bu durum, Arktik bölge güvenliği çabalarına ră̆men kıyıdaş devletlerarası ilişkilerde güvenlik ikilemi yaratmaktadır. Bu çalışma, uluslararası bir antlaşma ile hukuki statüsü olmayan Arktik bölgede kıyıdaş devletlerin güvenlik stratejileri ve çıkar çatışması temelinde korku ve güvenlik kaygılarının sonucu olarak ortaya çıkan güvenlik ikilemini realist ve liberal teoriler bağlamında ele almaktadır.

Anahtar Kelimeler: Arktik Bölge, Güvenlik, Güvenlik İkilemi, Realizm, Liberalizm. 


\title{
Arctic Security and Ongoing Security Dilemma in the Perspective of Realism and Liberalism
}

\begin{abstract}
The reclamation of sea and abyssal plain as a result of glacier melting with the reason of global warming ended by global climate change, its capacity of rich natural resources and the idea of its big potantial of easy access to new shipping trade routes make the Arctic crucial globally in terms of political and economic perspectives and transform it as a jeopolitical arena. The Arctic, today constitutes a rivalry area for - its riparian states named as 'Arctic Cinque' - the US, Russian Federation, Canada, Norway and Denmark in terms of those states' political and economic interests and those states increase their military precautions and investments on overland, airspace and sealand for preserving and controlling their political, economic and national security interests. This phenomenon creates a security dilemma among the rappian states relationships in spite of the efforts for Arctic security. This paper analyses the riparian states' security strategies on the Arctic that has no legal status by an international agreement and the Arctic security dilemma emerged as a result of the rappian states' fear and security concerns in the basement of interest conflict in the context of realism and liberalism.
\end{abstract}

Keywords: Arctic, Security, Security Dilemma, Realism, Liberalism. 


\section{Giriş}

Yaşam koşullarının neredeyse mümkün olmadığ1 Arktik bölge, son yirmi beş yıldır farklı disiplinler ve bilim insanları için önemli bir araştırma alanı olmayı sürdürmektedir. Küresel iklim değişikliğinin sonucu olarak küresel ısınmanın artması ile bölgedeki buzulların önemli oranda erimesi, deniz ve deniz tabanına ulaşımı mümkün kılmış ve böylelikle bölgenin sahip olduğu doğal kaynaklar tespit edilmeye başlanmıştır. Zengin doğal kaynaklarının yanı sıra bölge, deniz ticareti açısından yeni bir rota oluşturması açısından da stratejik bir önem arz etmektedir. Bu avantajları ile Arktik bölge, kendisine kıyıdaş devletlerarasında jeopolitik bir mücadele ve rekabet alanına dönüşmüştür. Amerika Birleşik Devletleri (ABD), Rusya Federasyonu (RF), Kanada, Norveç ve Danimarka kıyıdaş devletler olarak siyasi ve ekonomik ç1karları temelinde 20. yüzyılın başlarından itibaren bölge üzerindeki egemenlik iddialarını sürdürmektedirler. Kıyıdaş devletlerarasındaki egemenlik iddialarının günümüze değin çözüme kavuşmamasının en temel sebebi, bölgenin hukuki statüsü çizen henüz bir uluslararası antlaşmanın olmamasıdır. İlgili devletler, faaliyetlerini ikili anlaşmalarla gerçekleştirmektedir. Kıyıdaş devletlerarasındaki bu egemenlik çatışmasının altında yatan en önemli sebeplerden biri de enerji kaynaklarına hızlı ve kolay erişim sağlama isteğidir. Siyasi, ekonomik ve ulusal güvenlik kazanımları çerçevesinde kıyıdaş devletler, her geçen gün bölge üzerinde önleyici tedbirlerini ve askeri yatırımlarını arttırmakta ve bu durum kıyıdaş devletlerarasında güvenlik ikilemi yaratmaktadır. Bu durum ise, Arktik bölge güvenliğinin istikrarı açısından engel teşkil etmektedir.

Bölge üzerindeki mücadeleye tarihsel açıdan bakıldığında, 1920'lerde bölge sektörel açıdan kıyıdaş devletlerarasında paylaşılarak Kuzey Kutup noktası ilgili devletlerarasında sınır olarak belirlenmiştir. Kıyıdaş devletler egemenlik iddialarını (Kanada-1909; ABD-1924; Sovyetler Birliği (SSCB)1926) peş peşe ortaya koymuşlardır. Soğuk Savaş dönemine değin bölge, bu şekilde kıyıdaş devletlerin paylaşım esasları ilişkin faaliyet alanı olmuştur. Soğuk Savaş döneminde ise bölge, iki kutuplu sisteminin doğası gereği rekabetin ve mücadelenin çok sert olduğu alanlardan biri olarak uluslararası sistemde yer bulmuştur. Soğuk Savaş döneminde ABD ve SSCB, bölgeye hâkim olan tarafın Dünya'nın kontrolünü ele geçirebileceğine inanmaktaydılar. Arktik bölgenin coğrafik konumu gereği Moskova ve Washington arasındaki 
deniz mesafesini en aza indiren bir rota oluşturması, ABD'nin ve RF'nin iki kutuplu sistem içerisinde özellikle de ulusal güvenlikleri bağlamında bu düşünceye sahip olmalarında önemli etken olmuştur. Bölge, dönem içerisinde $A B D$ ve $S S C B$ tarafından yoğun şekilde askeri yapılanmaya maruz kalmıştır. Bu sayede bölge giderek politik ve güvenlik odaklı bir hal almaya başlamıştır.

Arktik bölge, tarihsel açıdan Soğuk Savaş döneminin tandemi içerisinde kazandığı jeostratejik önemi bugüne değin kazanmasa da son yirmi beş yılda gerçekleşen küresel iklim değişikliği sonucu küresel ısınmanın artması ile siyasi ve ekonomik açıdan jeopolitik bir önem kazanmış ve 21. yüzyılın coğrafi keşif alanı olarak özellikle kıyıdaş devletlerin mücadelesi bağlamında uluslararası politikanın ana gündem maddelerinden biri olmaya da devam etmektedir. Bu açıdan Arktik bölgenin jeopolitik önemi giderek artmaktadır. Bölgenin jeopolitik mücadele alanı açısından en büyük avantajı, sahip olduğu doğal kaynaklardır. Bölgenin yaklaşık olarak dünyada kanıtlanmış ve işlenmemiş doğal gaz rezervinin \%30'una, petrol rezervinin ise \%13'üne sahip olduğu, bu iki kaynağın maddi değerinin yaklaşık bir trilyon doların üzerinde olduğu ve bölgenin Suudi Arabistan'dan daha fazla fosil yakıta sahip olduğu tahmin edilmektedir. Arktik bölgenin sahip olduğu zengin doğal kaynakların \%84'ünün okyanus yatağında olması, Arktik Beşlisi açısından kıta sahanlığı sorununu gündeme taşımaktadır. Bu açıdan kıta sahanlığı sorunu, bölgede var olan jeopolitik mücadelenin temel sebebi konumundaki enerji kaynaklarına erişim mücadelesinin öncül adımını teşkil etmektedir. Günümüzde bölge üzerine en önemli tartışma konusu, kıta sahanlığının sınırlarının nereden geçeceğidir. Kaynakların çıkarılmasının şuan için yüksek maliyet arz etmesi ve deniz ticareti açısından yeni bir rota olarak hala okyanus yüzeyinin buzullarla kaplı olması bağlamında avantajlı olmaması, kıyıdaş devletlerarasında fiili bir çatışma durumu yaratmasa da ilgili devletler gelecek siyasi ve ekonomik çıkarları açısından şimdiden jeopolitik bir mücadele içine girmiş bulunmaktadırlar. Bu bağlamda kıyıdaş devletler, sürekli kıta sahanlığını genişletme çabasındadırlar. RF, bu amaçla Birleşmiş Milletler'e 20 Aralık 2001'de ilk başvurusunu, 2015 yılında ikinci başvurusunu yapmış ve 16 Ağustos 2019 tarihinde Birleşmiş Milletler Kita Sahanlığ1 Komisyonu nihai kararını vererek Lomonosov ve Medeleev sıradağları deniz alanları ile Podvodnikov havzasının RF kıta sahanlığı içerisinde olduğunu beyan etmiştir 
(Staalesen, 2019). RF'nin ilgili bölgeleri kıta sahanlığının içerisine almak istemesinin sebebi ise zengin petrol ve doğal gaz yataklarının bu bölgelerde bulunmasıdır.

Soğuk Savaş'ın sona ermesi ile bölgedeki ABD - SSCB rekabeti azalmış, tamamen olmasa da askeri yapılar azalmıştır. Böylelikle Arktik bölge, güvenlik dışı (güvenlik dışılaştırma) kapsama taşınmıştır. Kıyıdaş devletlerin çıkarları temelinde kıta sahanlığı sorunu, ilgili devletler tarafınca 1982 tarihli Birleşmiş Milletler Deniz Hukuku Sözleşmesi (BMDHS) esas alınarak çözüme kavuşturulmuştur. Soğuk Savaş sonrası süreçte Arktik devletleri arasında çok taraflı iş birliği geliştirilerek bölge kaynaklarının ve faunanın korunması ile olası çevre sorunlarına çözüm arayan ortak çalışma programları oluşturulmuştur. Bu doğrultuda atılan ilk adım 4 Temmuz 1991 tarihinde imzalanan Arktika Çevre Koruma Stratejisi (The Arctic Environmental Protection Strategy - AEPS) belgesidir. Strateji belgesi, kıyıdaş devletlerarasında iş birliğinin arttırılıp 19 Eylül 1996 tarihinde sürdürülebilir kalkınma ve çevre sorunlarının tartışıldığ 1 platform olarak Arktik Konsey'in deklarasyon niteliğinde kurulmasını sağlamıştır. Ancak Arktik Konsey, uluslararası hukuki bir statüye sahip olmamakla birlikte iyi niyet sözleşmesi niteliği taşımaktadır (Bloom, 1999, s.712). Arktika Konseyi'nin, kurucu belgesi olan Ottawa Beyannamesi'nde "Arktika Devletleri" olarak nitelenen ve aynı zamanda Konsey'in daimi üyesi olan sekiz devlet şunlardır: Amerika Birleşik Devletleri, Danimarka, Finlandiya, İsveç, İzlanda, Kanada, Norveç ve Rusya Federasyonu. Bu devletlerden Finlandiya, İsveç ve İzlanda, Kuzey Kutup (Arktika) dairesi içerisinde olmalarına rağmen Arktika Okyanusu'na kıyıları yoktur. Bu sebeple, bu devletlerin Arktika'daki toprak paylaşımıla ilgili talepleri bulunmamaktadır. Görüldüğü üzere, 1990-2000 yılları arası dönemde kıyıdaş devletlerin yapıcı rol üstlenmeleri ve çok taraflı işbirlikleri ile Arktik bölge olumlu gelişmelere tanıklık ederken 2000 sonrası süreçte bu olumlu gelişmeler yerini yeniden alevlenen kıyıdaş devletlerin sınır ve kıta sahanlığ tartışmalarına bırakmıştır. Kıyıdaş devletlerin 2000 sonrası süreçte bölgeye ilişkin güvenlik temelli politikalar üretmesi, askeri yapılanmaya ve silahlanmaya ağırlık vermesi, ilgili devletlerarasında ulusal güvenliklerine yönelik korku ve tehdit algısı bağlamında güvenlik ikilemi yaratmaktadır. Arktik Beşlisi'nin bu dönemde bölgeye yeniden önem duymasının üç temel nedeni arasında bölgenin sahip olduğu jeostratejik önem, hidrokarbon ve biyolojik kaynak 
zenginliği ve deniz ticaret rotaları açısından sahip olduğu avantaj yer almaktadır. Anlaşıldığı üzere, günümüzde de Arktik bölgede kıyıdaş devletlerin enerji kaynakları ve deniz ticaret yolları üzerindeki rekabeti, siyasi ve ekonomik çıarları temelinde devam etmekte ve bu durum Arktik bölge güvenliği üzerinde olumsuz bir etkiye sahip olmakla birlikte kıyıdaş devletlerarasında süregelen güvenlik ikilemi yaratmaya devam etmektedir. Bölge güvenliğinin sağlanması ve ortaya çıkan güvenlik ikilemi durumunun ortadan kalkması açısından iki temel yaklaşım söz konusudur. Bunlar; bölgede barış ve istikrara kurumsallaşmış uluslararası iş birliği ile odaklanan liberal teori ile bölgesel çatışmaların çıkmasına sebep olacak doğal kaynaklar ve ekonomik çkarlar adına girilen yarışın varlığını ortaya koyan realist teoridir.

Bu çalışmanın amacl, Arktik bölge güvenliğinin hali hazırda sağlanamamasının sebeplerini kıyıdaş devletlerin ilgili güvenlik stratejilerini ve kendi aralarında oluşan güvenlik ikilemi durumunu realist ve liberal güvenlik anlayışı çerçevesinde analiz ederek açıklamaktır. Çalışmada öncelikle realizm ve liberalizm açısından güvenlik anlayışlarına yer verilecektir. Ardından k1yıdaş devletlerin iç ve dış politikaları bağlamında Arktik güvenlik stratejileri analiz edilecektir. Çalışmanın son bölümünde ise Arktik güvenlik ikileminin oluşma süreci ele alınacaktır.

\section{Realist ve Liberal Güvenlik Anlayışı}

Uluslararası sistem, güvenlik hususunda devinim içerisinde çeşitli evrelerden geçmektedir. Bu evreler, değişimin temel dinamiği olmakta ve dönem itibari ile yer alan güvenlik algılamaları ve değişim arasındaki ilişkiyi belirlemektedir. Raymon Aron'un değişim kanununda belirttiği üzere, bir yerin askeri, demografik ya da ekonomik değeri savaşma ve üretim teknikleri ile insan ilişkileri ve kurumlarla birlikte değişmektedir (Dursun, 2017, s.75). Süreç içerisinde bu ve benzeri değişimlerden uluslararası sistem etkilenmiş ve neticede sistem değişiklikleri yaşanmıştır. Bu değişiklikler yeni entegrasyon ve sistem biçimleri doğurmuş̧tur. Doğası itibari ile entegrasyonun değişimle ilgili bir kavram olduğu da düşünülürse güvenlik kavramının uygulama ve algılama boyutu ile ilgili gerçekleşen "ilerlemeler" ya da gelinen nokta açıkça görülebilecektir (Arı, 2002, s.446). Güvenlik kavramının uluslararası ilişkiler teorileri içerisinde ele alınıp değerlendirilmesi, özellikle değişim ile güvenlik 
arasındaki ilişkinin ve kavramın genişlemesi ile kavrama ilişkin yeni düşüncelerin (kapsayıcı güvenlik gibi) ortaya atılma sürecinde literatürdeki temellerinin ortaya konulması açısından önem arz etmektedir. Bu durumda durağan bir alan olduğunu söylemek mümkün değildir. Kavram içeriksel ve anlamsal açıdan II. Dünya Savaşı'ndan günümüze evrilmiş, dönüşümlere uğramıştır (Waever, 1995, s.50). Bu dönüşüm devletten bireye doğru yol alan bir süreçtir. Bu süreçte birçok teoriden söz etmek mümkündür. Teorilere değinilecek olursa, iki temel yaklaşımın varlığı çıkış noktasını oluşturmaktadır. Bu teorik yaklaşımlardan ilki temellerini Hobbes'tan alan geleneksel, devlet merkezli, realist yaklaşım; diğeri ise Grotious'un fikirleri ile filizlenen globalisttransnasyonalist devlet merkezli olmayan yaklaşımdır (Sullivan, 1989, s.8-9). Devlet merkezli teoriler geleneksel devletçi yaklaşım olarak da ifade edilmektedir. Bu yaklaşımlar realist dünya politikaları okumasına sahiptirler. Buna göre güvenlik söz konusu olduğunda devletler dünya politikaları analizlerinin merkezindedir ve uluslararası ilişkiler terimi devletlerin etkileşimi olarak açıklanmaktadır (Jones, 1999, s.95).

Realizm; 'Devlet Merkezli' yaklaşımlar içerisinde geleneksel yaklaşım olarak ifade olunan realizmde, bir diğer kullanımla da Buzan' in realist orthodoxy olarak ele aldığı klasik realizmde uluslararası politika saf güç mücadelesine dayanmakta ve güvenlik gücün bir türevi olarak ele alınmaktadır (Buzan, 1995, s.2-3). Realist teoriler açısından güvenlik ikilemi ise devletleri savaşa zorlayan nedenlerin başında gelmektedir. Siyasal birimler arasındaki güvenlik rekabeti de liderleri güç kavramını politikalarının merkezine almaya zorlamaktadır (Herz, 1950, s.25). Klasik realizmin önemli temsilcilerinden Morgenthau (1952) güç ve güvenlik ikileminin yanına çıkarı; devletin fiziksel, siyasi ve kültürel kimliğini diğer devletlerin müdahalelerinden koruma gücü olarak klasik realizmin güvenlik anlayışına eklemiştir (p. 972). Realist teoride uluslararası politikayı en iyi şekilde ifade eden çıkar kavramının temel unsuru güçtür. Güç merkezli bir hareket noktasında da devletlerin uygulamalarına karşı evrensel ahlak prensiplerine başvurulamayacağı açıktır (Morgenthau, 1948, s.7-8). Bu durum temel aktör olan devletlere sürekli güvenlik kaygısı yaratmaktadır. Bu kaygı, uluslararası sistemde devletlerin olası her türlü saldırılara karşı her zaman güvende olamayacakları düşüncesinden ortaya çıkmaktadır. Güç, özellikle de askeri güç devletlerin değişmez araçları arasında yer almaktadır. Öte yandan realizmin 'güncel' yorumu ola- 
rak ifade edilen neorealizmin fikir babası Kenneth Waltz, uluslararası politikaların değişimlerini sorgulamakta ve dönüşümü ortaya koymaktadır (Waltz, 2000, s.6). Waltz (2000), güvenliği uluslararası sistemin anarşik yapısında devletlerin davranışlarının odağında görmekte ve bu bağlamda da anarşik yapı içerisinde 'güvenlik' devletler açısından en temel amaç olup devletler sürekli güvenlik arayışına girmektedirler. Ancak uluslararası sistemin anarşik yapısı içerisinde devletler için mutlak güvenlik söz konusu değildir. Bununla beraber devletler güvenliklerini arttırmak ve korumak için mücadele etmektedirler. Güvenlik, devletlerin davranışlarını belirleyerek temel hedef olma özelliğini korumaktadır. Bu açıdan devletler rekabetin ve düşmanlıkların olduğu bir ortamda güvenlik çıkarını koruyup kollamak durumundadırlar. Bu bağlamda güvenlik algısına yönelik realizm ve neorealizmin birbirlerinden farkını şu şekilde özetlemek mümkündür: Neorealizm, gücü devletin varlığını sürdürmesi ve güvenliği sağlamasının aracı olarak görmekte ve güvenlik neorealizmde bağımsızlık ve otonomi ile eşdeğer bir anlama sahiptir. Neorealist yaklaşıma göre devletlerarasındaki iş birliği s1nırlı olmakta ve bu duruma kendi aralarındaki güvenlik rekabeti sebep oluşturmaktadır (Ozcelik, 2005, s.92-93; Ozcelik, 2018a, s.3-4).

Liberalizm, siyasal düşünce açısından belirlenmiş amaçları ve hedefleri gerçekleştirmeyi ilke edinmiştir. Siyasal ve ekonomik düşünce açısından 18. ve 19. yüzyıllarda etkili olan liberalizmin yayılma sahası öncelikle İngiltere ve $A B D$ olmuştur. Liberal düşüncenin temelini eşitlik, özgürlük ve mülkiyet hakkı gibi kavramlar oluşturmaktır. Liberalizmin güvenlik anlayışında temel husus, güvenlik ile özgürlük arasında denge sağlanabilmesidir (Uğuz, 2016, s. 89). Bu açıdan liberalizmde devletin temel görevi, içeride ve dışarıda güvenliği sağlamakla birlikte bireysel özgürlüklere de zarar vermemek adına gerekli önlemleri almaktır. Liberal düşüncede, güvenliği sağlamak devletin var olmasının yegâne sebebidir. Bireysel özgürlüklere önem atfedilen liberalizmde devlet, güvenliği sağlarken bireysel özgürlüklere belirli kısıtlamalar getirebilir. Realizm gibi liberalizm de uluslararası sistemin anarşik yapısının varlığını kabul etse de güvenliğin sağlanması hususunda uluslararası iş birliğine dikkat çekmektedir. Liberalizm özellikle Soğuk Savaş sonrası yumuşama döneminde düşünsel açıdan önem kazanmıştır. I. Dünya Savaşı sonrasında savaşları önleme ve uluslararası güvenlik bağlamında barış çabaları liberalizmi doğururken II. Dünya Savaşı liberalizmin gelişimine ket vurmuştur. Ancak artan barış çabaları, realizmin karşısına neoliberalizmi çıkarmıştır. 
Karşılıklı iş birliğine dayalı güvenlik anlayışına sahip olan liberal teoriye göre taraflar arasındaki iş birliği arttı̆̆ sürece karşılıklı kazanç da artmaktadır. İşbirliği aynı zamanda tarafların birbirlerine yönelik tehdit algılarını da azaltmaktadır. Liberalizmin güvenlik anlayışı çerçevesinde savaşlar, uluslararası sistemin anarşik yapısından ziyade aktör olarak devletlerin birbirlerini yanlış anlamalarından çıkmaktadır. Uluslararası güvenlik ve barış, uluslararası hukuk kurallarına bağllık ve karşılıklı iş birliği çerçevesinde inşa edilebilir. Diğer bir ifadeyle liberalizm, uluslararası güvenliğin ve barışın uluslararası kurumlar vasitasıly tesis edilebileceğini savunmakta ve bu bağlamda kurumsallaşmaya önem vermektedir. Dünya tarihinin sadece çatışmalardan ibaret olmadığını aynı zamanda iş birliğinin de bulunduğunu belirten liberal kuramclar, yanlış algılamalara ve güvensizliğe neden olacak koşulların düzeltilmesi durumunda çatışma ve rekabetin azalabileceğini, devletlerin birbirleriyle iş birliği yapabileceğini vurgulamaktadır. Özetle, uluslararası örgütlerin ve kurumların iştiraki ile uluslararası iş birliği ve dünya barışı sağlanabilmektedir (Ozcelik, 2018b, s.65-66; TUIC). 20. yüzyılda etkili olan neoliberalizm, klasik liberalizmin referans noktası olan birey yaklaşımından hareket ederek uluslararası iş birliği ve barış konularını analiz etmektedir. Çoğulcu bir yaklaşımla demokrasi temel ilke olarak ele alınmaktadır. Bu bağlamda uluslararası güvenliğin inşası da uluslararası kurumların iş birliği, demokrasiye ve uluslararası hukuk kurallarına bağlı kalınması ile inşa edilebileceği savunulmaktadır.

\section{Kıyıdaş Devletlerin Arktik Politikaları ve Güvenlik Stratejileri}

Arktik güvenliği özellikle Soğuk Savaş döneminin sona ermesi ile kıyıdaş devletlerin kendi aralarında ve bölgesel ve küresel aktörlerin iş birliği neticesinde bir değişim yaşamıştır. Bugün hala devam eden temel sorun kıta sahanlığı çözüme kavuşmasa da bazı sınır sorunları ikili ya da çok taraflı antlaşmalar ile olumlu neticelenmiştir. 1990 yılında ABD ve RF arasında Bering Denizi'ndeki sınır sorununu çözüme kavuşturan antlaşma, 2010 yılında RF ve Norveç arasında Barents Denizi'ndeki sınır sorununu çözüme kavuşturan antlaşma ve 1996 yılındaki Ottowa Deklarasyonu ile hükümetlerarası yapıya kavuşan Arktik Konseyi bölgesel iş birliği adına önemli örnekler arasında gösterilmektedir. Bahse konu olumlu gelişmelere rağmen kıyıdaş devletlerin 
bölgedeki enerji kaynaklarına ulaşma ve deniz ticaret yollarını kontrolleri altında tutma gibi çıkarları temelinde kıta sahanlığı sorunu tırmanarak devam etmektedir. Yeni bir jeopolitik mücadele alanı olarak ortaya çıkan Arktik bölgede kıyıdaş devletlerarasındaki çıkar çatışmaları ve ilgili devletlerin ulusal güvenlik politikaları bağlamında Arktik güvenliğine ilişkin farklı güvenlik stratejileri geliştirdikleri görülmektedir. Diğer bir ifadeyle kıyıdaş devletlerarasındaki rekabet sertleşerek devam etmektedir (Bostan ve Ozcelik, 2017, s.922).

ABD'nin Arktik bölgesine kıyıdaş devlet olması, 1867 yılında RF'den Alaska'yı satın alması ile gerçekleşmiştir. ABD, 1924 yılında Kuzey Kutbu'nun Alaska'nın bir uzantısı olduğunu iddia etmişse de 2007 yılına kadar bölgedeki en önemli husus olan Soğuk Savaş döneminin mirası askeri ve güvenlik kaygıları bağlamında durağan bir politika izlemiştir. Ne var ki, RF'nin 2007 yılında Arktik deniz tabanına titanyum Rus bayrağını dikmesi sonrasinda ABD bölgeye yüzünü dönmüss ve 2009 yılında Goerge W. Bush'un imzası ile "Birleşik Devletler Arktik Politikası" belgesi yayınlanarak ABD ilk kez kendini Arktik devleti olarak deklare etmiştir (Heininen, 2012, s.22-23). ABD, 2013 yılında da "Arktik Bölgesi İçin Ulusal Strateji” belgesi ile bölgeye yönelik önceliklerini revize etmiştir. ABD Savunma Departmanı'nın (Department of Defense-DoD) 2019 yılı Temmuz ayında yayımladığı Arktik strateji raporuna göre ABD'nin Arktik güvenlik stratejisi; bölgeye ilişkin farkındalığın arttırılması, operasyon ağının genişletilmesi ve bölgede hukuksal yapının güçlendirilmesi esaslarına dayanmaktadır (DoD, 2019). ABD'nin bölgede stratejik caydırma sisteminin belirli bir kısmının, erken uyarı sistemlerinin ve küresel füzesavar savunma sistemlerinin konuşlandırılmış olması bağlamında Arktik bölgenin karmaşık güvenlik yapısı, ABD'nin bölgeye ilişkin güvenlik stratejisini etkilemektedir. $\mathrm{ABD}$, bu hususta özellikle bölgede bugün itibariyle 14 buzkıran gemisine ve 6 kutup üssüne sahip ve ticari yatırımlarını hızlandıran RF'nin bölgedeki artan askeri unsurları ile yarattığı güvenlik tehdidine dikkat çekmektedir.

ABD'nin bölgesel politikasına bakıldığında, temel öncelik ulusal güvenlik olup Arktik devletlerarasında iş birliğine ilişkin kurumların etkinliğinin arttırılması ve bölge ile ilgili alınacak kararlarda yerel halkın katılımını sağlamaktır. ABD'nin Arktik bölgedeki ulusal güvenlik çıkarları arasında füze savunma ve erken uyarı; stratejik yük taşıma için deniz ve hava sistemleri konuşlandırma, stratejik caydırma, deniz varlığı ve deniz güvenlik faaliyetleri; 
seyrüsefer ve uçuş güvenliğini sağlamak yer almakta olup deniz serbestîsi, Amerikan yönetimi tarafından "en üst ulusal öncelik" olarak belirlenmiştir (Ateş, 2017, s.24). ABD'nin ulusal güvenlik çıkarlarını ve dolayısıyla Arktik güvenlik stratejisini etkileyen etmenler arasında; bölgenin değişen fiziksel çevresi, işbirliklerinin arttırılmaması, artan askeri faaliyetler, bölgenin deniz ticaret yolları açısından yarattığı rekabet, bölgeye ilişkin yönetimsel sorunlar yer almaktadır. Öte yandan ABD, uluslararası örgütlerin ve kuruluşların bölgedeki savunma stratejisini ve egemenlik haklarını olumsuz etkileyeceği hususundaki kaygılarını sıklıkla gündeme getirmektedir. Bu açıdan, BM Deniz Kıta Sahanlığı Komisyonu'nun RF'nin kıta sahanlığını genişletme talebine 2019 yllında nihai olarak olumlu karar vermesi örnek olarak gösterilebilir. Bu bağlamda ABD'nin bölgeye ilişkin politika uygulamalarında daha çok tek taraflı ya da iki taraflı bir yaklaşım içerisine girdiğini söylemek mümkündür. ABD bölgedeki ulusal güvenlik çıkarlarını ABD'nin ev sahibi olduğu Arktik bölge, paylaşlan Arktik bölge ve stratejik rekabette potansiyel bir koridor olarak Arktik bölge şeklinde üç aşamada oluşturmaktadır. Bölgeye ilişkin güvenlik stratejilerinin uygulanması açısından ABD, NATO'nun bölgedeki faaliyet ve etki alanını genişletme çabasındadır. NATO'nun bölgede etkin konuma geçmesi, ABD açısından RF'nin askeri açıdan bölgede yalnızlaşması anlamına gelmektedir. ABD, bölgede yeni uluslararası kurumların varlığını kendi çıkarları açısından reddetmekle birlikte mevcut antlaşmalarla bölgedeki faaliyetlerini sürdürmek istemektedir. Diğer bir ifadeyle, bölgede gücün dağılmasına karşı bir tutum içerisindedir. RF'nin bölgedeki saldırgan ve yayılmacı yaklaşımı ve Çin'in "Bir Kuşak-Bir Yol" projesi temelinde "Kutup İpek Yolu" projesi ile 2013 yılından itibaren Arktik Konsey'inde gözlemci statüsüne sahip olması bağlamında 2018 yılında kendini "yakın Arktik devleti" ilan etmesi, ABD'nin bu tutumunu derinleştirmektedir. Her ne kadar uluslararası hukuk kurallarına ve uluslararası iş birliğine vurgu yapsa da ABD'nin bölgeye ilişkin siyasi, ekonomik ve güvenlik yaklaşım ile stratejilerinde ulusal çıkarları doğrultusunda hareket ettiği ve bölgede lider konumundaki Rusya ile yer altı kaynaklarına ilişkin rekabet çerçevesinde askeri yatırımlara ağırlık vererek jeopolitik ve jeoekonomik üstünlük elde etmeye çalışmaktadir.

Rusya Federasyonu, kıyıdaş devlet olarak Arktik bölgede en geniş topraklara sahiptir. Bölgedeki toprak alanı, RF'nin tüm toprak alanının \%60'ına karşılık gelmektedir. RF'nin “Yüksek Kuzey Rusya” olarak adlandırdığı Arktik 
bölge, RF'nin petrol ve doğalgaz kaynaklarının \%52'sine sahip olması bağlamında ekonomi ve dış politika açısından RF'nin can damarı konumundadır. 14. yüzyılda gerçekleştirilen coğrafi keşifler dışında RF bölgeye yönelik ilk adımını, SSCB döneminde bölgenin bilimsel ve sanayi açısından araştırılması için "Yüksek İktisat Kurulu Kuzey Bilimsel - Sanayi Keşif Heyeti (Sevekspeditsiia)"nin kurulması ile atmıştır. Ayrıca SSCB'nin merkez yürütme kurulunun 15 Nisan 1926 tarihli yayınladığı mıntıka ilkesi ile keşfedilmiş ve keşfedilecek yerlerde egemenlik hakkını sürdüreceğini beyan etmesi, günümüze değin RF'nin bölgedeki egemenlik iddialarının temelini oluşturmuştur. Çarlık döneminde toprak genişletme çabaları ile gündeme gelen Arktik bölge, SSCB döneminde ulusal güvenlik ve ekonomi bağlamında gündemde yer bulmuştur. SSCB döneminde kalkınma planları içerisinde yer verilen Arktik bölge, ilgili araştırma ve keşif kurullarının arttırılan bütçeleri ile önem kazanmıştır. Ancak bölgeye ilişkin ilgili kurulların çalışmalarının yetersiz kalması, kaynakların verimli kullanılamaması ve I. Dünya Savaşı sonrası RF'nin askeri ve ekonomik açıdan daralması bölgeye yönelik hedeflerin gerçekleştirilmesini yavaşlatmıştır. Yine de SSCB'nin Baltık - Beyaz Deniz kanalını inşa etmesi ve Kuzey Denizi Rotası'nı aktif hale getirme çalışmaları, bölgede askeri ve ekonomik açıdan var olma amacının önemli göstergesidir. Soğuk Savaş döneminde ise, SSCB bölgeye ABD tehdidi bağlamında askeri odaklı bakış sergileyerek bölgedeki hava sahalarını, askeri üslerini ve karakollarını arttırmıştır. SSCB çıkarları bağlamında Arktik bölgesinin iktisadi açıdan kalkınmasına öncelik vererek bölgedeki sanayi yatırımlarını arttırmıştır. Bu doğrultuda SSCB'nin temel amacı, bölgede insan kaynakları ile doğal kaynakları bir arada değerlendirmek olmuş ve bununla da SSCB'nin "Kuzey Hâkimiyet" düşüncesi oluşmuştur (Anderson, 2010, s.523). SSCB döneminde RF, Arktik bölgede ulusal güvenliği ve ekonomik çıkarları temelinde önemli ilerleme kaydetse de özellikle Soğuk Savaş döneminde silahlanmaya ayırdığı yüksek bütçeler ve SSCB'nin sistemsel olarak birçok açıdan hantallaşması, bölgeye yönelik politikaları ve çalışmaları geriletmiştir. Ancak bu duruma rağmen RF'nin bu dönemde de Arktik bölgedeki etkin konumunun ve varlığının sürdüğünü söylemek mümkündür.

SSCB'nin 1991'de yıkılması ile askeri ve iktisadi açıdan zorlu bir döneme giren RF, öncelikle iç politikada yapılanma ile istikrar önceliğine ve ekonomik kalkınmaya odaklanmış, Arktik bölgeye ilişkin yayılmacı politikasından uzaklaşmıştır. Hatta bu dönemde Arktik bölgedeki SSCB mirası askeri üsler 
terk edilmiştir. 1990 - 2000 yılları arasındaki toparlanma süreci sonrası RF, Arktik bölge üzerindeki politikalarına hız vermiştir. İlk adım olarak 2001 yllında BM Kıta Sahanlığı Komisyonu'na kıta sahanlığını genişletme talebinde bulunmuştur. RF, bölgedeki yayılmacı politikalarına bu girişimleri ile devam ettiği gibi yayınladığı strateji belgeleri ile de bölge üzerindeki amaç ve hedeflerini ortaya koymaktadır. Nitekim RF'nin 2008 yılında yayınladığ 1 “2020 ve Sonrası RF Arktik Bölgesi Devlet Politikası Temelleri"' adlı strateji belgesinde Arktik bölgesine ilişkin ulusal çıkarlarını, "Arktik bölgesinin RF'nin ekonomik ve sosyal kalkınmasında stratejik bir kaynak olarak kullanılması, bölgenin barış ve iş birliği alanına dönüştürülmesi ve Kuzey Denizi Rotası'nın kullanımı" şeklinde tanımlamaktadır (DW, 2008). Strateji belgesi, Arktik bölgenin RF'nin ulusal güvenliği ve enerji kaynaklarına ulaşımı açısından önemine de dikkat çekmektedir. RF'nin belgede stratejik öncelikler bağlamında özellikle bölgedeki sorunların çözümü, güvenliğin sağlanması ve çalışmaların gerçekleştirilmesi açısından uluslararası iş birliği üzerinde önemle durduğu görülmektedir. 2013 yılında RF tarafından yayınlanan diğer strateji belgesi (RF Arktik Bölgesi Kalkınma Stratejisi), 2008 tarihli belgedeki hedefleri ve stratejileri kapsamakta olup belgede Arktik bölgesinin RF'nin sosyo-ekonomik kalkınmasındaki yeri ve önemine odaklanılarak bölgenin RF ulusal güvenliği kapsamında hâkim güç olarak kontrol altında tutulmasının gerekliliği vurgulanmaktadır. İlgili strateji belgelerinde görüldüğü üzere RF'nin bölgedeki temel amacı, ulusal güvenlik ve ekonomik çıkarları çerçevesinde Arktik bölgenin ulusal kaynak merkezi haline getirilmesidir. Ayrıca, RF'nin ulusal güvenlik stratejilerinde, askeri ve deniz doktrinlerinde de bölgeye yönelik amaçlarına ve stratejilerine önemle yer verdiğini söylemek mümkündür. RF, bölgeye yönelik yukarıda bahse konu tüm belgelerinde yer verdiği amaç ve stratejilerine yer verdiği amaç ve stratejilerine dayanak ve destek olan askeri politikalarını da fiilen uygulama çabasındadır. RF, bölgeye yönelik mevcut çıkarlarının güvencesi olarak bölgedeki askeri varlığını temel dayanağı olarak görmektedir. Soğuk Savaş döneminden bugüne Arktik bölge, RF'nin ulusal güvenliği adına stratejik öneme sahip olmaya devam etmektedir. Bu bağlamda RF, bölgede birçok askeri üs, radar üsleri, telsiz haberleşme sistemleri gibi askeri yapılanmalara yoğun bir şekilde yer vermeye devam etmektedir. Heininen, Sergunin ve Yarovoy (2014) RF'nin Arktik bölgeye ilişkin askeri politikalarının hedefleri arasında Rus egemenliğinin Arktik bölgede varlığgnın devam ettirilmesinin, bölgedeki RF'nin ekonomik çıarlarının korunması 
gerekliliğinin ve RF'nin küresel ölçekte askeri güç kapasitesinin ortaya konmasının yer aldığını ifade etmektedir (s. 79). RF bölgede her geçen gün askeri kapasitesinin güçlenmesi için yatırımlarını arttırmaktadır. Bu açıdan bakıldığında da, RF'nin nihai amacının Arktik bölgenin ulusal kaynak olarak merkezi haline getirilmesi olduğu görülmektedir.

Arktik bölgeye en uzun kıyıya sahip ikinci kıyıdaş devlet olarak Kanada, ekonomik, siyasi ve toplumsal açlardan bölgeye oldukça önem vermektedir. Nitekim 2010 yılında yayınlanan "Kanada'nın Arktik Stratejisi” belgesinde Arktik bölgenin Kanada için birçok açıdan önemli olduğa şu açılardan değinilmektedir: "Arktik bölge, Kanada'nın ulusal kimliği açısından temel oluşturmaktadır. Bölge ayraca Kanada'nın tarihine ve kültürel yapısına ışık tutmakta olup gelecek için önemli bir potansiyele sahiptir. Bu bağlamda, bölgede egemenliğin mutlak korunması gereklidir (Bergh, SIPRI, 2012)". Kanada bölgeye ilişkin politikalarını uygulamak adına egemenliğin sürdürülmesi, bölgedeki ekonomik ve toplumsal kalkınmayı ulusal çıarlar bağlaminda desteklemek ve bölgenin yönetiminde aktif rol üstlenmek şeklinde temel stratejilere sahiptir. Kanada'nın bölgeye ilişkin egemenliğin sürdürülmesi kapsamında temel sorunları arasında sınırlar, kıta sahanlıklarının genişletilmesi ve uluslararası hakların kazanımları yer almaktadır. Kanada 2013 yılında mevcut sorunların çözümü için BM Kıta Sahanlığı Sınırları Komisyonu'na başvurmakla birlikte Arktik Konseyi içerisinde de diplomatik faaliyetlerini de yoğun şekilde sürdürmektedir. Kanada'nın bölgeye ilişkin temel sınır iddiaları arasında Danimarka ile Hans Adası sinır sorunu olup halen çözüme kavuşturulamamıştır. Diğer çözüme ulaştırılamayan önemli bir sınır sorunu da ABD ile olan Kuzeybatı Geçidi'dir. Kanada, geçidi Arktik takımadalar içerisinde görüp kendi iç suları olarak değerlendirmekte iken ABD, geçidin uluslararası sular içinde olduğunu iddia etmektedir. Öte yandan Kanada, bölgede on beş yılı aşkın süredir askeri kapasitesini kara, hava ve deniz güçleri ile arttırmaktadır. Kanada silahlı kuvvetleri bölgede arama kurtarma ekibi, bölgesel güvenlik birlikleri, hava ve deniz radar ve plotlama sistem ve gözlem merkezleri inşa etmekte ve sayılarını her geçen gün arttırmaktadır. Özellikle Kanada deniz donanması, Arktik bölgede en fazla sayıda devriye gemisine sahip olmakla dikkat çekmektedir. Kanada Milli Savunma Bakanlığı'nın 2019-2020 yılı bütçesi içerisinde çevre ve iklim değişikliği ile mücadele bağlamında Arktik bölgenin askeri yapılanması adına ayrılan 21.8 milyon dolarlık bütçe dikkate alındığında Kanada'nın da diğer kıyıdaş devletler gibi 
bölgede silahlanma yarışında olduğunu söylemek mümkündür (Sevunts, 2019).

Kıyıdaş devletlerarasında RF ile sıkı iş birliği içerisinde olan Norveç'in Arktik bölgeye ilişkin ilgi ve faaliyetlerinin ana nedeni, ekonomik ve siyasi temele dayanmakla birlikte özellikle Kuzey Denizi'ndeki petrol ve doğalgaz üretiminin düşmesidir. Bilindiği üzere Norveç 1980'li yıllardan bu yana dünyada doğalgaz tedarik zincirinde ikinci sırada yer almaktadır. Ayrıca petrol üretiminde de önemli bir kapasiteye sahip olan Norveç'in petrol geliri, ülke gelirinin üçte birini oluşturmaktadır. Ancak Norveç, petrol ve doğalgaz üretiminin düşmesi ile oluşacak ekonomik etkinin izlerini Arktik bölgedeki iddiaları ve kazanımları ile telafi etmeye çalışmakta ve bu hususta RF ile ortak ticari faaliyetlerde bulunma çabası içine girmektedir. Norveç' in bölgeye ilişkin temel stratejileri arasında bölgede egemenliğinin tanınması ve bölge kaynaklarından stratejik iş birlikleri ile yararlanma yer almaktadır. Norveç'in bölgeye yönelik girişimleri ve hak iddiaları 2005 Soria Moria Deklarasyonu ile hız kazanmıştır. Deklarasyon ile Norveç özellikle kuzey bölgesi stratejisini ekonomik, politik ve güvenlik çıkarları temelinde belirlemiştir. 2006 yılında Norveç hükümeti Arktik bölge strateji belgesi yayınlayarak "Yüksek Kuzey" olarak ifade ettiği Arktik bölgedeki hedeflerini ortaya koymuştur. Belgede özellikle kaynakların geliştirilmesi, ortak güvenlik organizasyonun yapılandırılması, RF ile iş birliği ve kıta sahanlığı gibi konulardaki hedeflere yer verilmektedir. Belge, hedefler bağlamında Arktik bölgede Norveç'in egemenliğinin ve ulusal güvenliğinin korunmasına ilişkin askeri yapılanmalara da vurgu yapmaktadır. Bu bağlamda Norveç' in 1949'da NATO'ya üye olması, özellikle iş birliği içinde bulunulan RF ile ilişkilerin ikilem içerisinde yürümesine sebep olmakta ve her iki devlet özelinde Svalbard bölgesi ve Arktik bölgedeki silahlanma yarışı açısından günümüze değin çözülemeyen sorunlar yaşanmaktadır. Görüldüğü üzere, Norveç de Arktik bölgede özellikle ekonomik çıkarlarının korunup sürdürülmesi açısından kıyıdaş devletler ile silahlanma da olmak üzere birçok açıdan rekabet halindedir.

Danimarka'nın Arktik bölge ile bağ kurmasını sağlayan ve hak iddialarına sebep olan alanlar, Grönland ve Faroe adalarıdır. Stratejik açıdan Grönland adası, Danimarka için öncelikli konumdadır. Danimarka Dışişleri Bakanı Lene Espersen, Faroe Adaları Özerk Bölgesi Hükümet Temsilcisi Kaj Leo Holm Johannesen ve Grönland Özerk Bölgesi Hükümet Temsilcisi Kuupik Kleist' in ortak imzaları ile deklare ettikleri 2011-2020 strateji belgesinde 
Arktik bölgenin güvenliği adına silahlandırılmamasına, ortak koruma programların gerekliliğine ve kıyıdaş devletlerin yoğun iş birliği içinde olmalarına vurgu yapılmaktadır. Özellikle kıyıdaş devletlerarasındaki sınır anlaşmazlıklarının uluslararası hukuk kuralları ile çözüme kavuşturulmasının altı çizilmektedir (Jon Rahbek-Clemmensen, Arctic Yearbook 2016). Bu bağlamda Danimarka'nın temel hedefinin Arktik bölgede stratejik öncelikleri ile çıkarlarını korumak ve küresel bir aktör olarak statüsünü güçlendirmek niyetinde olduğunu söylemek mümkündür. Ayrıca Danimarka'nın bölgeye ilişkin ekonomik çıkarlardan ziyade siyasi önceliklere yer verdiği görülmektedir. Silahlanma karşıtı bir tutum sergilemesine rağmen Danimarka, kıyıdaş devletlerarasındaki rekabet bağlamında Grönland ve Faroe adaları yönetimleri ile ortak güvenlik birimleri kurma çalışmalarını da sürdürmektedir.

Görüldüğü üzere, kıyıdaş devletlerin Arktik politikaları ve güvenlik stratejileri liberal yaklaşım çerçevesinde inşa edilmeye çalışılsa da ulusal çıkarların, güvenliğin ve egemenlik haklarının korunması bağlamında uygulamalarda realist yaklaşıma yer verildiği gözlemlenmektedir.

\section{Güvenlik İkilemi ve Süregelen Teorik İkilem Durumu}

Dünya üzerinde ekonomik, politik ve stratejik artan önemi ile Arktik bölge, özellikle kıyıdaş devletlerin önemli rekabet alanına sahne olmaktadır. Bu aç1dan kıyıdaş devletler, ekonomi, dış ve güvenlik politikalarında Artiktik bölgeye ilişkin önemli bir yer ve değer vermektedirler. Kıyıdaş devletlerin stratejik yaklaşımlarının temel hedefi ise bölgeye yönelik ekonomik ve güvenlik çıkarlarının korunması ve sürdürülmesidir. Bu bağlamda kıyıdaş devletlerin bölgede öncelikli olarak askeri kapasitelerini ve kabiliyetlerini arttırma çabası içine girdiklerini söylemek mümkündür. Kıyıdaş devletler, rekabet ortamında hava, deniz ve kıyı güvenliği açısından askeri üs, karargâh, vb. unsurlarla bölgedeki güçlerini arttırmak ve egemenliklerini koruma çabasındadırlar. Kıyıdaş devletler dışında Finlandiya, İsveç, İzlanda, Avrupa Birliği, Çin ve Hindistan da bölgeye yönelik ekonomik, politik ve güvenlik çıkarları bağlamında yayınladıkları strateji belgeleri ile rekabet alanında paydaş olma çabasındadırlar. Büyük bir rekabet alanına dönüşen Arktik bölgedeki çıar mücadelesinde Arktik Konsey üyeleri ve diğer devletleler ile uluslararası yapılar bölgenin uluslararası hukuk kuralları çerçevesinde iş birliğine dayalı şekilde korunması ve bölgeye ilişkin faaliyetlerin sürdürülmesini dile getirseler de 
özellikle kıyıdaş devletlerin ulusal çıkarları ve güvenlikleri bağlamında bölgede silahlanmaya ağırlık vermeleri barışçıl yaklaşımları ve uygulamaları sekteye uğratmaktadır. Ayrıca bu durum bölge güvenliğini tehdit ettiği gibi kıyıdaş devletlerarasında süregelen bir güvenlik ikilemi durumu yaratmaktadır. Bilindiği üzere, bölge Soğuk Savaş döneminden itibaren ABD ve RF'nin nükleer caydırıcılığında önemli bir role sahiptir. Kıyıdaş devletlerin bölge üzerindeki ekonomik, politik ve güvenlik çıkarlarını korumak ve olası tehditlere karşı askeri unsurlarla cevap verme niyetleri, mevcut ilişkilerdeki güvenlik ikilemine de ivme kazandırmaktadır. Bahse konu güvenlik ikileminin oluşmasındaki temel nedenin kıyıdaş devletlerin barış çabalarına yönelik niyet belirsizliklerinin ve tehdit algısına yönelik askeri güç ile karşılık verme çabalarının olduğunu söylemek mümkündür. Diğer bir açıdan bakılacak olursa, Arktik bölge güvenliğinin inşa sürecinde üyelerin Konsey içerisinde liberal söylem ve yaklaşım sergilemelerine rağmen pratikte savunma ve saldırı dengesi üzerinden her devletin bireysel olarak güvenliği inşa etme çabasinda olduğu görülmektedir. Kıyıdaş her devletin aldı̆̆ı askeri önlem ya da güç artırımı, diğer devletler açısından ulusal güvenliklerine tehdit olarak algilanmakta ve bu durum da döngüsel bir silahlanmanın artışına yol açmaktadır. Bu bağlamda kıyıdaş devletlerin söylemde liberal yaklaşım, pratikte ise realist bir yaklaşım sergilediklerini ortaya koymaktadır. Kıyıdaş devletlerin bölgeye ilişkin stratejilerinde de bölgede barış ve güvenliğin iş birliği içerisinde tesis edilmesi gerekliliğine vurgu yapılmasına rağmen ilgili devletlerarasındaki ilişkilerde "niyet belirsizliği, güvenlik kaygısı, tehdit algısı ve uluslararası hukuk kurallarının uygulamada yetersizliği'” gibi düşünce ve durumların varlığı, ilişkilerdeki güvenlik ikilemine zemin oluşturmakta ve 1şık tutmaktadır. Ortaya çıkan güvenlik ikilemi durumu, rekabeti daha da sert koşullar içine sürüklemekte ve kıyıdaş devletlerin güvenlik ve tehdit algısını olumsuz etkileyerek bölgedeki silahlanma yarışına ivme kazandırmaktadır (Ozcelik, 2019, s.19).

Arktik bölgede kıyıdaş devletlerarasındaki var olan güvenlik ikilemine ve çok yönlü rekabete rağmen bugün itibariyle bölge askeri ve politik açıdan durağanlığını korumaktadır. Bu hususta özellikle Soğuk Savaş sonrası dönemde bölgesel iş birliği çabalarının ve Arktik Konsey'in etkili olduğunu söylemek mümkündür. Ancak 2000 sonrası dönemde kıyıdaş devletlerarasındaki rekabet çok yönlü olarak hızlı bir şekilde artmış ve günümüzde de devam etmektedir. Tansiyonun düşük olmasına rağmen Arktik bölge, güvenlik 
ikileminin dinamiklerini giderek artan bir şekilde kendi içerisinde barındırmaktadır. Arktik bölge sahip olduğu zengin doğal kaynakları ile küresel öncü bir bölge olma özelliğini sürdürdügüü sürece de kıyıdaş ya da kıyıdaş olmayan devletlerin ulusal çıkarlarının çatışma merkezi olmaya devam edecektir. Bu hususta, devletlerin ortak güvenlik inşasından ziyade ulusal çıkarları bağlamında bireysel güvenlik inşasına askeri güç ile yönelmeleri temel esas teşkil etmekle birlikte ortaya çıkan güvenlik ikilemi sarmalında yer almalarını tercihleri önemli rol oynamaktadır. Diğer bir ifadeyle, kıyıdaş devletler çıkar, güç ve güvenlik bağlamında Arktik bölgedeki strateji ve uygulamaları açısından realist bir yaklaşım içerisinde olmaya devam ederken Arktik Konsey ve diğer uluslararası örgütler içerisinde uluslararası iş birliği ve ortak güvenlik inşası söylemleri ile liberal bir yaklaşım sergileyerek teorik ikilem içerisinde de kaldıkları görülmektedir. Ayrıca kıyıdaş devletlerin politik ve askeri açıdan karar alıcılarının içindeki bulundukları güvenlik ikilemi seviyesinin de ikilemi yorumlama ve cevaplama seviyeleri bağlamında yönetilebilir olmadığı ve bu durumun devletlerarasındaki ilişkilerdeki güvenlik ikileminin sürerlilik haline temel dayanak oluşturduğu görülmektedir.

\section{Sonuç}

Sahip olduğu zengin doğal kaynakları ve yeni deniz ticareti güzergahlarına erişim kolaylı̆̆ı sağlaması açısından kıyıdaş ve kıyıdaş olmayan devletler nezdinde giderek önem arz eden ve jeopolitik bir rekabet alanına dönüşen Arktik bölge, 21. yüzyılın politik, ekonomik ve güvenlik açısından en önemli tartışma ve rekabet alanlarından birini oluşturmaktadır. Özellikle kıyıdaş devletlerin ekonomik ve ulusal güvenlik çıkarlarını ve bölgedeki egemenlik haklarını korumak adına bağımsız stratejiler geliştirmesi ve bireysel hareketle silahlanma girişimleri, Arktik bölge güvenliği üzerinde tehdit algısı oluşturmakla birlikte kıyıdaş devletlerarası ilişkilerde de güvenlik ikilemine sebep olmaktadır. Arktik Konsey, uluslararası örgütler ve uluslararası organizasyonlar içerisinde kıyıdaş devletlerin ortak güvenlik inşasına ve kurumlararası iş birliği diyalog çalışmalarına liberal yaklaşım ile vurgu yapmalarının söylemde ya da dikkate değer olmayan uygulamalarda kalması, bölge güvenliğinin oluşturulmasına engel teşkil etmektedir. Bu duruma ilişkin önemli sebeplerden biri de bölgenin uluslararası hukuk kuralları bağlamında 
hukuki bir statüye sahip olmamasıdır. Diğer bir önemli sebep de kıyıdaş devletlerin kendilerine yönelik tehdidi, askeri tehdit olarak algılamaları neticesinde bu tehdidin ortadan kaldırılması adına silahlanma yarışına girerek güvenlik ikilemi durumunun yaratılmasıdır.

Kıyıdaş devletlerin ekonomik ve ulusal güvenlik çıkarları ile bölgedeki egemenlik haklarını korumaları bağlamında güç mücadelesini klasik (askeri) güç kapsamında ele aldıkları, bölgeye yönelik politikalarını uygulamada, stratejik hedef bağlamında da kendi aralarındaki rekabeti askeri güç kapasitesinin arttırılması ile taçlandırdıkları görülmektedir. Bu bağlamda kıyıdaş devletlerin bölgeye yönelik stratejilerinde söylem açısından liberal yaklaşıma yer verdiklerini, uygulamada ise realist yaklaşımı benimsediklerini söylemek mümkündür. Bu durum da kıyıdaş devletlerarası ilişkilerdeki güvenlik ikileminin sürerlilik arz etmesine ve bölgede iş birliğinden yoksun bir güvenlik anlayışının oluşmasına sebep olmaktadır. 


\title{
EXTENDED ABSTRACT
}

\section{Arctic Security and Ongoing Security Dilemma in the Perspective of Realism and Liberalism}

\author{
Murat Yorulmaz \\ Trakya University
}

Having estimated $30 \%$ of undiscovered natural gas reserves and $13 \%$ of undiscovered oil reserves in the World, the Arctic has turned into a geopolitic rivalry region in terms of economy, trade and security in particular. At first, the riparian states (the U.S., Russia, Canada, Denmar and Norway) have started to take measurements to preserve their economic and national security interests. The struggles of the riparian states on the region in the basement of preserving their national security has recently led to increase the level of their military facts and investments, and armaments in the aspects of sea, air and land in the region. The rivalry among the riparian states has mostly escalated on protecting national interests. This phenomenon and the military based developments have led to a security dilemma among the riparian states in spite of the cooperation among them for the Arctic security. In fact, all members of the Arctic Council have appreciated because the Arctic has a low-tension structure, encirled by colloborater and peaceful states which aim to construct welfare and cooperation in the region. On the other hand, both the riparian states and the exterior ones have highlighted the significance of International Law for unresolved issues and conflicts in the region. Apart from the favourable ideas and explanations, in particular, if the riparian states maintain to increase their military capabilities and measurements, to preserve their national interests in the Arctic, the other ones will perceive them as a threat for their national securities. This may in turn necessitate countermeasures against their neighbors' countermeasures, and so on, potentially setting off a process that none of the involved actors neither wants nor anticipates - an "incremental militarization" of the region (Atland, 2012, s.3). It is possible to say that there is lack of certainity in terms of the riparian states' intentions. Besides, the riparian states historically and constatntly maintain to declare their sovereignty claims on the region. The main aim is to reach the natural 
resources for the riparian states. In this context, one of the main issues discussed is the claims on continental shelf among the riparian states. It can be said that the issue of continental shelf is the one of the main reasons of the geopolitical rivalry in the region. Although the riparian states do not take out the oil and natural gas because of the high costs and geographical challenges, they want to set stage for their national interests in the future. In the Cold War period, the region, in particular, gained the strategical importance for the parties in the aspect of security in the bipolar system. After the period of Cold War, the rivalry between the U.S. and the Soviet Union decreased, and so the region set in a desecuritization position. In the years of 1990-2000, the Arctic met with the riparian states' favourable plans and colloborations such as the declaration of Arctic Council (1996) and the Arctic Environmental Protection Strategy (1991). The approaches centered peace and multilateral cooperations continued till the 2000s. After the 2000s, the riparian states started to produce security centered policies related to the region, and so the rivalry in the region again increased. This led to reveal security dilemma among the riparian states and it has still gone on today.

As a concept security is deal with alteration in the international system. Thus, security concept is analysed within its changing meaning and alterations in the international system in the theories of the discipline. International relations (IR) theories have different perceptions on security. As one of the most significant concepts in IR, security means in general that it is the position of safety of states and their citizens. It is hard to determine a concrete definition of security because of its alteration in time. It is commonly that there are many different meanings and definitions of security as in theoretical perspectives. For Realism, security means national security which refers to national interest. Security is deal with power and power depends on states' military capabilities. The security of one's own state is likely to be enhanced at the expense of another state in what has been termed the security dilemma; for Realists the security dilemma is averted by their faith in the balance of power (Hough, 2008, s.3). On the other hand, the main aim is to construct a blance between security and freedom in terms of Liberalism. Besides, the state should provide and constitute security internally and externally but all precautions should also be provided not to be a obstacle for individuals' freedom. Providing and presenting security to citizens is one of the main reasons of state's existence. Like Realism, Liberalism accept that international system 
has an anarchic structure and nation states are the most significant actors of international system, but liberalism gives more attention to other acteors such as transnational corporations, interest groups, intergovernmental organizations (IGOs) and non-governmental organizations (NGOs).

In conclusion, the riparian states construct their Arctic policies in the centre of their national security and economic interests. It is seen that they actually present a realist approach in the example of their armament rivalry in the region, bit on the other hand they present a liberal approach in the examples of declaration of Arctic Council, the Arctic Environmental Protection Strategy and multilateral cooperations. In fact, the riparian states' dual approaches in terms of their behaviors and attitudes to the region in themselves provide a source for the security dilemma among them. The other significant reason for the security dilemma is the armament of the riparian states in the context of their national interests in spite of their peaceful discourses.

\section{Kaynakça / References}

Anderson, D. (2010). Settlers on the Edge: Identity and Modernization on Russia's Arctic Frontier. By Niobe Thompson, Slavic Reviews, 69(2), 523-524.

Arı, T. (2002). Uluslararası ilişkiler teorileri çatışma hegemonya işbirliği. İstanbul: Alfa Yayınları.

Ateş, O. (2017). Rusya Federasyonu'nun arktika politikası. Yayımlanmamış Yüksek Lisans Tezi, İstanbul Üniversitesi, İstanbul.

Atland, K. (2012). Overcoming the Arctic Security Dilemma. Paper prepared for the $53^{\text {rd }}$ Annual Convention of the International Studies Association, San Diego, http://files.isanet.org/ConferenceArchive/b6e6953d374446d 1a05cee 38d34b2480.pdf adresinden erişildi.

Bergh, K. (2012). The arctic policies of Canada and The United States: Domestic motives and international context. Stockholm: SIPRI Insights on Peace and Security, 30 Mayıs 2020 tarihinde www.sipri.org adresinden erişildi.

Bloom, E. (1999). Establishment of the Arctic Council. The American Journal of International Law, 93(3), 712-722.

Bostan, A. ve Ozcelik, S. (2017). The Arctic Land as a Security issue. IV. IBANESS Congress Series, Russe, Bulgaria, April 08-09, 2017, D. K. Dimitrov, D. Nikoloski ve R. Yılmaz (eds.), Proceeeding Book s.922, ISBN: 978-619-203177-0. 
Buzan, B. (1995). Security, the State, the New World Order and Beyond. (Ed. R. D. Lipschutz), On Security, içinde (s.187-211), New York: Columbia University Press.

Clemmensen, J. R. (2016). An arctic great power'? Recent developments in Danish Arctic Policy. Arctic Yearbook, 23 Mayss 2020 tarihinde https:// arcticyearbook.com/images/yearbook/2016/Scholarly Papers/13.Rahbek .pdf adresinden erişildi.

DoD. (2019). Department of defense arctic strategy. 26 Mayss 2020 tarihinde https://media.defense.gov/2019//Jun/06/2002141657/-1/-1/1/2019-DODARCTIC-STRATEGY.PDF adresinden erişildi.

Dursun, H. R. (2017). Realizmin realist bir eleştirisi olarak Raymond Aron ve uluslararası ilişkiler kuramı. Marmara Üniversitesi Siyasal Bilimler Dergisi, 5(2), 67-85.

DW. (2008). Russia must cement claim over arctic resources, Medvedev Says, 27 Mayss 2020 tarihinde https://p.dw.com/p/F]k7 adresinden erişildi.

Heininen, L. (2012). State of the arctic strategies and policies: A Summary. Arctic Yearbook içinde (s.2-47), 26 Mayıs 2020 tarihinde https://arcticyearbook .com /images/yearbook/2012 / Scholarly Papers /1. Heininen.pdf adresinden erişildi.

Heininen, L., Sergunin, A. ve Yarovoy, G. (2014). Russian studies arctic: Avoiding a new cold war. Valdai Discussion Club Grantees Report, 30 Mayis 2020 tarihinde http://vid-1.rian.ru/ig/valdai/arctic eng.pdf adresinden erişildi.

Herz, J. H. (1950). Political realism and political idealism, A study in theories and realities. Chicago\&London: The University of Chicago Press.

Hough, P. (2008). Understanding Global Security. Oxford: Routledge.

Jones, W. R. (1999). Security, strategy and critical theory. London: Boulder, Lynne Rienner.

Motgenthau, H. J. (1948). Politics among nations. New York: Knopf.

Morgenthau, H. J. (1952). Another greate debate: The national interest of the United States, American Political Science Review, 46(4), 961-988.

Ozcelik, S. (2005). 1990'lu yıllarda uluslararası ilişkiler ve çatışma çözümünde neorealizm ve Neo-Gramsiyan hegemonya kavramı. Ekonomik ve Sosyal Arastirmalar Dergisi, 1, 88-114.

Ozcelik, S. (2018a). The Cold War Re-Visited: Explaining and understanding of the end of the Cold War in light of neo-realism. The Turkish Yearbook of International Relations, 49, 1-20. 
Ozcelik, S. (2018b). Institutional approaches to international organization and global governance, (Ed. N. Doğan ve V. Şeyşane), International Organization and Global Governance, içinde (s.63-93), Eşkişehir: Anadolu University Press.

Ozcelik, S. (2019). An introduction to security studies, (Ed. N. Doğan), International Security, içinde (s.3-33), Eskişehir: Anadolu University Press.

Staalesen, A. (2019). Russia is winning support for its claims on Arctic shelf, says chief negotiator. 21 Mays 2020 tarihinde https:// thebarentsobserver .com/en Larctic/2019/11/russia-winning support-its-claims-arctic-shelf-says-chiefnegotiator adresinden erişildi.

Sevunts, L. (2019). Canada's 2019 budget slim on hard power Arctic commitments, experts say. Eye on The Arcric, 03 Haziran 2020 tarihinde https://www.rcinet.ca/eye-on-the-arctic/2019/03/21/2019-budget-arctic-military/ adresinden erişildi.

Sullivan, M. P. (1989). Power in contemporary international politics. Columbia: University of South Carolina Press.

TUIC. (2014), Teoriler ışı̆̆ında güvenlik algısı. 25 Mayıs 2020 tarihinde http://www.tuicakademi.org/teoriler-isiginda-guvenlik-algisi/ adresinden erişildi.

Uğuz, A. (2016). Liberalizmde güvenlik kavramı ve uluslararası güvenliğe getirilen çözümler, $V$. Türkiye Lisansüstü Çalışmalarn Kongresi - Bildiriler Kitabı II. İçinde (s.85-98) . DOI:10.12658/ TLCK .5. 2.B006.

Waever, O. (1995). Securitization and desecuritization. (Ed.: R. D. Lipschutz), On Security, içinde (s.46-86), New York: Columbia University Press.

Waltz, K. (2000). Structural Realizm After The Cold War. International Security, 25(1), 5-41.

\section{Kaynakça Bilgisi / Citation Information}

Yorulmaz, M. (2020). Realizm ve liberalizm perspektifinde arktik bölge güvenliği ve süregelen güvenlik ikilemi. OPUS-Uluslararası Toplum Araştırmaları Dergisi, 16(32), 5250-5273. DOI: 10.26466/opus.773799 